\title{
Toxidez por ácido acético em arroz sob diferentes valores de pH da solução nutritiva
}

\author{
Acetic acid toxicity in rice under different $\mathrm{pH}$ values of nutritional solution
}

\author{
Magali de Ávila Fortes ${ }^{\mathrm{I}}$ Rogério Oliveira de Sousa $^{\mathrm{II}}$ Fabiana Schmidt $^{\mathrm{I}}$ \\ Ledemar Carlos Vahl ${ }^{\mathrm{II}}$
}

\section{RESUMO}

A proporção das formas associadas e dissociadas do ácido acético é dependente do pH. O aumento do $\mathrm{pH}$ favorece a dissociação do ácido acético, o que pode diminuir seu efeito tóxico para o arroz, pois moléculas com carga são menos solúveis nos componentes lipídicos das membranas celulares. $O$ objetivo deste trabalho foi determinar os efeitos do $\mathrm{pH}$ da solução nutritiva referentes à toxidez pelo ácido acético em plantas de arroz. $O$ experimento foi conduzido em solução nutritiva, em bancada de laboratório com fornecimento de luz artificial. Os tratamentos foram dispostos em um fatorial $4 \times 2$, em delineamento inteiramente casualizado, com três repetições, e foram testados os fatores: $\mathrm{pH}$ da solução nutritiva $(3,7 ; 4,7 ; 5,7 ; 6,7)$ e ácido acético (testemunha sem ácido $e$ $2,5 \mathrm{mmol} \mathrm{L}^{-1}$ de ácido). O incremento nos valores de $\mathrm{pH}$ de 3,7 a 6,7 reduziu o efeito tóxico do ácido acético nas plantas de arroz, aumentando o comprimento da raiz em $90 \%$ e da parte aérea em 37\%. Houve aumento nos teores de $\mathrm{N}$ em $22 \%$ e diminuição nos teores de Ca em 19\% na mesma faixa de $\mathrm{pH}$ na presença do ácido acético. Os efeitos tóxicos do ácido acético sobre as plantas de arroz foram atenuados com o aumento do pH de 3,7 para 6,7.

Palavras-chave: ácidos orgânicos, decomposição anaeróbia, acidez.

\section{ABSTRACT}

The proportion of forms associated and undissociated acetic acid depends on $\mathrm{pH}$. The increment of $\mathrm{pH}$ induced the dissociation of acetic acid that may reduce the toxicity of rice, therefore, molecules with charge are less soluble in lipidics components of cellular membranes. The research objective was to estimate the effect of different $\mathrm{pH}$ values in nutritional solution on toxicity of acetic acid on rice. The experiment was conducted in nutritional solution in laboratory with artificial light supplied. The treatments were arranged in factorial $4 \times 2$, in completely randomized design, with 3 replications, where the following factors were tested nutritional solution $\mathrm{pH}$ (3.7; 4.7; 5.7 and 6.7) and acetic acid (zero and $2.5 \mathrm{mmol} \mathrm{L}^{-1}$ of acid). The increment on $\mathrm{pH}$ values from 3.7 to 6.7 reduced the toxic effect of acetic acid in rice plants, increasing the radicular system in $90 \%$ and shoot in $37 \%$. It increased the $N$ content in $22 \%$ and reduction on Ca content in $19 \%$ in plants in same values of $\mathrm{pH}$ on presence of acetic acid. The toxic effect of acetic acid in rice plants were attenuated with $\mathrm{pH}$ increment from 3.7 to 6.7 .

Key words: organic acids, anaerobic decomposition, acidity.

\section{INTRODUÇÃO}

Nos solos de várzea com altos teores de matéria orgânica ou naqueles em que forem adicionados resíduos orgânicos, a atividade dos microrganismos anaeróbios é maior e a redução do solo é mais acentuada, ocorrendo maior liberação de nutrientes para a solução do solo e maior produção de substâncias tóxicas. Entre as substâncias tóxicas produzidas destacam-se os ácidos orgânicos de cadeia curta, como os ácidos acético, propiônico e butírico, pela quantidade produzida e pelos efeitos que causam nas

\footnotetext{
IPrograma de Pós-graduação em Agronomia. Departamento de Solos, Faculdade de Agronomia Eliseu Maciel (FAEM), Universidade Federal de Pelotas (UFPel), Pelotas, RS, Brasil.

IIDepartamento de Solos, FAEM, UFPel, CP 354, 96010-900, Pelotas, RS, Brasil. E-mail: rosousa@ufpel.tche.br. *Autor para correspondência.
} 
plantas de arroz (SOUSA, 2001). O ácido acético é produzido em maior quantidade (BOHNEN et al., 2005).

Os ácidos monocarboxílicos, entre eles, o acético, alteram a composição dos ácidos orgânicos na membrana plasmática, promovendo um decréscimo da proporção dos ácidos polinsaturados, afetando propriedade importante da membrana como a seletividade e aumentando o extravasamento de solutos (MARSCHNER, 1995). Assim, os ácidos orgânicos podem prejudicar o desenvolvimento da cultura, principalmente, pela inibição da elongação das raízes e da absorção de nutrientes (TAKENAGA, 1995a; SOUSA\& BORTOLON, 2002).

A intensidade da toxidez varia em função de vários fatores, tais como tipo e concentração do ácido (RAO \& MIKKELSEN, 1977), tolerância genotípica (KOPP et al., 2007) e pH. Entre esses fatores o pH do meio de cultivo apresenta efeito importante, visto que afeta a permeabilidade das membranas aos ácidos (MARSCHNER, 1995). Variações de pH alteram a proporção das formas associadas e dissociadas dos ácidos, o que pode determinar uma maior ou menor absorção pelas plantas. A constante de dissociação do ácido acético é pK=4,7, o que significa que a $\mathrm{pH} 4,7$ ele se encontra $50 \%$ dissociado na forma de acetato e $50 \%$ não dissociado na forma de ácido (ATKINS \& JONES, 2001). Então, em pH superior a 4,7, o predomínio da forma dissociada pode diminuir a toxidez, pois moléculas com carga positiva ou negativa são menos absorvidas que moléculas neutras (MARSCHNER, 1995).

Em solos alagados, o $\mathrm{pH}$ tende a neutralidade após as primeiras semanas de alagamento (PONNAMPERUMA, 1972), quando predomina a forma dissociada dos ácidos, que é considerada inofensiva às plantas (HARPER \& LYNCH, 1981). Em relação à massa global do solo livre de raízes, está correto afirmar isso, mas, na situação real da rizosfera, é diferente. O $\mathrm{NH}_{4}^{+}$é a forma de $\mathrm{N}$ predominante nesses solos e sua absorção causa um desequilíbrio de cátions em relação aos ânions absorvidos, o que é compensado pela extrusão de $\mathrm{H}^{+}$, causando gradientes de acidez entre a rizosfera e a massa do solo livre de raízes (TAKENAGA, 1995b). Além disso, a oxidação do $\mathrm{Fe}^{2+}$ na rizosfera também causa diminuição do $\mathrm{pH}$. Portanto o objetivo deste trabalho foi determinar os efeitos do pH da solução nutritiva sobre a toxidez pelo ácido acético em plantas de arroz.

\section{MATERIAL E MÉTODOS}

O experimento foi conduzido em solução nutritiva no Laboratório de Nutrição de Plantas do
Departamento de Solos da FAEM/UFPel, em bancada com fornecimento de luz artificial. A solução nutritiva apresentou a seguinte composição: $2,0 \mathrm{mmol} \mathrm{L}^{-1} \mathrm{de} \mathrm{N}$; 1,5mmol L-1 de Ca; $1,2 \mathrm{mmol} \mathrm{L}^{-1}$ de K; $1,2 \mathrm{mmol} \mathrm{L}^{-1}$ de P; 1,0 $\mathrm{mmol} \mathrm{L}^{-1} \mathrm{de} \mathrm{Cl} ; 1,25 \mathrm{mmol} \mathrm{L}^{-1} \mathrm{de} \mathrm{Mg} ; 1,26 \mathrm{mmol} \mathrm{L}^{-1} \mathrm{de}$ S; 0,0091 $\mathrm{mmol} \mathrm{L}^{-1}$ de Mn; 0,0001 $\mathrm{mmol} \mathrm{L}^{-1}$ de Mo; 0,0231 $\mathrm{mmol} \mathrm{L}^{-1} \mathrm{de} \mathrm{B} ; 0,079 \mathrm{mmol} \mathrm{L}^{-1} \mathrm{de} \mathrm{Cu} ; 0,090 \mathrm{mmol}$ $\mathrm{L}^{-1}$ de Fe e $0,0015 \mathrm{mmol} \mathrm{L}^{-1}$ de $\mathrm{Zn}$. A luz artificial foi composta de 45 lâmpadas amarelas de 100 Watts e 45 lâmpadas fluorescentes de 40Watts, colocadas sobre as plantas em uma altura de $80 \mathrm{~cm}$ da borda dos vasos. As plantas receberam luz por 10 horas ao dia e foram mantidas a temperaturas diurnas de $29^{ \pm} 2^{\circ} \mathrm{C}$ e noturnas de $24^{ \pm} 2^{\circ} \mathrm{C}$. Os tratamentos foram dispostos em um fatorial $4 \times 2$, em delineamento inteiramente casualizado, com três repetições, quando foram testados os seguintes fatores: $\mathrm{pH}$ da solução nutritiva $(3,7 ; 4,7$; 5,7; 6,7), e ácido acético (testemunha sem ácido e 2,5 $\mathrm{mmol} \mathrm{L}^{-1}$ de ácido). A concentração de ácido foi determinada em função de ser capaz de causar $30 \%$ de redução do comprimento radicular em pH 4,7 (SOUSA \& BORTOLON, 2002).

Sementes de arroz da variedade BRS 7 foram pré-germinadas no interior de duas camadas de esponjas de $1 \mathrm{~cm}$ de espessura e colocadas em vasilha plástica contendo água destilada, para que se mantivessem úmidas. Após a germinação das sementes, quando a radícula apresentou aproximadamente $2 \mathrm{~cm}$ de comprimento, foi realizada uma seleção das plântulas mais uniformes, que foram transferidas para vasos plásticos de 21 de volume contendo 21 de solução nutritiva. Estes foram cobertos com tampa de isopor perfurada onde foram acoplados pequenos discos de isopor com uma incisão da extremidade para o centro, permitindo a sustentação das plântulas.

Foram cultivadas três plantas por vaso por um período de 21 dias com a solução renovada a cada sete dias. Após este período, a solução nutritiva foi trocada, aplicando-se a essa $1,5 \mathrm{~mL}$ de ácido acético, dando a concentração final de $2,5 \mathrm{mmol} \mathrm{L}^{-1}$. No tratamento testemunha, a solução foi renovada sem a adição do ácido. $\mathrm{O}$ pH da solução nutritiva foi ajustado diariamente aos valores estabelecidos a cada tratamento, pela adição de $\mathrm{HCl} 0,5 \mathrm{~mol} \mathrm{~L}^{-1} \mathrm{Ou} \mathrm{NaOH}$ $0,5 \mathrm{~mol} \mathrm{~L}^{-1}$. A solução nutritiva foi trocada após sete dias. As plantas foram colhidas após um período de 10 dias sob efeito dos tratamentos.

Foram avaliados, nas plantas de arroz, os parâmetros morfológicos (comprimento, raio e área) do sistema radicular segundo TENNANT (1975). A massa de matéria seca do sistema radicular foi determinada por pesagem após secagem em estufa a $60^{\circ} \mathrm{C}$. O comprimento da raiz principal foi medido aos 21 dias, 
por ocasião da aplicação do ácido acético e ao final do experimento, obtendo-se assim o crescimento da raiz na presença do ácido acético. Foi realizada a avaliação da estatura das plantas logo após a coleta das plantas e da massa de matéria seca da parte aérea que foi realizada após secagem em estufa a $60^{\circ} \mathrm{C}$. A concentração de macronutrientes nas plantas foi avaliada segundo métodos descritos em TEDESCO et al. (1995) e a quantidade total acumulada foi calculada a partir da concentração dos nutrientes em relação à massa de matéria seca da parte aérea.

Os dados obtidos foram submetidos à análise de variância, Teste de Duncan a 5\% de probabilidade (para comparação da presença do ácido) e análise de regressão polinomial (para a comparação dos níveis de $\mathrm{pH}$ ) utilizando o programa estatístico Winstat (MACHADO, 2001). Os valores da variável independente $(\mathrm{x})$ correspondem aos diferentes valores de $\mathrm{pH}$ e os valores da variável dependente (y) aos indicadores avaliados.

\section{RESULTADOS E DISCUSSÃO}

O comprimento total, a área, o raio e a massa de matéria seca radicular aumentaram com o incremento do $\mathrm{pH}$ na presença de ácido acético, enquanto que na ausência deste o pH não afetou aqueles indicadores (Figura 1). Houve interação significativa entre os fatores pH e ácido acético para esses indicadores. Observa-se que o maior efeito do ácido acético ocorreu no pH 3,7, e que a partir de 4,7 as diferenças em relação à testemunha sem ácido foram pequenas. O crescimento da raiz principal foi o único indicador significativamente afetado pelo pH na ausência do ácido acético, apresentando um efeito matemático quadrático, não explicável do ponto de vista biológico. Já o efeito inibitório do ácido acético para este indicador pode ser verificado nos quatro valores de $\mathrm{pH}$.

A estatura das plantas e a massa de matéria seca da parte aérea (Figura 2) aumentaram com o incremento nos valores de $\mathrm{pH}$, na presença de ácido acético. A interação entre os fatores $\mathrm{pH}$ e ácido acético foi significativa. Não houve efeito significativo na estatura das plantas e na massa de matéria seca da parte aérea do arroz em relação aos valores de $\mathrm{pH}$ na ausência de ácido acético. $\mathrm{O}$ pH não apresentou um efeito direto sobre o crescimento das plantas, mas sim, um efeito indireto devido a sua interferência na intensidade da toxidez pelo ácido acético. Segundo MENGEL \& KIRKBY (1987), as plantas crescem normalmente em amplas faixas de $\mathrm{pH}$, desde que deficiência e toxidez nutricional estejam controladas, o que justifica a ausência de efeito do $\mathrm{pH}$ nos parâmetros avaliados na ausência de ácido acético.
O pH do meio de cultivo é um fator importante na determinação da fitotoxidez por ácidos orgânicos, pois afeta as proporções das formas dissociadas e não-dissociadas dos ácidos. O aumento do $\mathrm{pH}$ condiciona uma maior dissociação do ácido acético, aumentando a proporção da forma dissociada do ácido (LYNCH, 1986). Moléculas neutras atravessam mais facilmente as membranas celulares que moléculas eletricamente carregadas (MARSCHNER, 1995; TAIZ \& ZEIGER, 2004), o que, segundo MARSCHNER (1995), pode explicar a diminuição da toxidez por ácidos orgânicos com o aumento do pH.

Em pesquisa realizada por RAO \& MIKKELSEN (1977), também foi observada uma menor inibição no crescimento radicular do arroz devido ao aumento do $\mathrm{pH}$ e este efeito foi atribuído à dissociação dos ácidos orgânicos. No entanto, o efeito do pH variou de acordo com o ácido considerado, pois a redução do pH de 5 para 3 proporcionou maior toxidez para o ácido acético que para o propiônico, e quase não afetou a toxidez por ácido butírico, embora as constantes de dissociação dos mesmos sejam semelhantes, sendo $\mathrm{pK}=4,81$ para o ácido butírico e $\mathrm{pK}=4,87$ para o ácido propiônico. Variações dos efeitos tóxicos dos ácidos podem ocorrer entre os experimentos, pois outros fatores estão relacionados à toxidez. Entre os quais, destaca-se o aumento no número de carbonos na cadeia do ácido, tempo em que as plantas ficam sujeitas às concentrações tóxicas e diferenças no grau de tolerância dos genótipos de arroz (KOPP et al., 2007).

Resultados semelhantes foram obtidos também por CAMARGO et al. (1993) com os ácidos acético e butírico, porém com o pH entre 4 e 6 . Os autores observaram reduções de $60 \%$ e $66 \%$ no comprimento e na área radicular, respectivamente. Neste trabalho verificou-se uma redução de $47 \%$ no comprimento radicular e 69\% na área radicular com o pH diminuindo de 6,7 para 3,7 na presença do ácido acético (Figura 1).

O efeito negativo do ácido acético neste trabalho foi observado tanto no crescimento da parte aérea, como da raiz, mas o maior efeito inibitório ocorreu no crescimento radicular. Outros autores também têm verificado que a parte da planta mais sensível aos efeitos de ácidos orgânicos é o sistema radicular. CAMARGO et al. (1993) observaram que, na presença de ácido acético, o crescimento e o acúmulo de matéria seca radicular reduziram em $51 \%$ e $35 \%$, respectivamente, e $68 \%$ e $70 \%$, respectivamente, na presença de ácido butírico. SOUSA \& BORTOLON (2002) verificaram uma inibição de 50\% no crescimento do sistema radicular do arroz com uma concentração de $4,7 \mathrm{mmol} \mathrm{L}^{-1}$ de ácido acético em solução nutritiva, enquanto que na parte 
a)

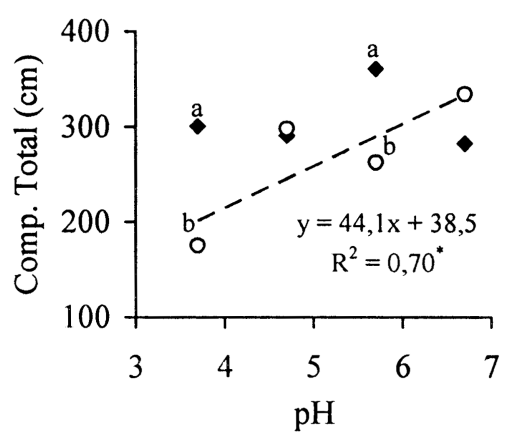

c)

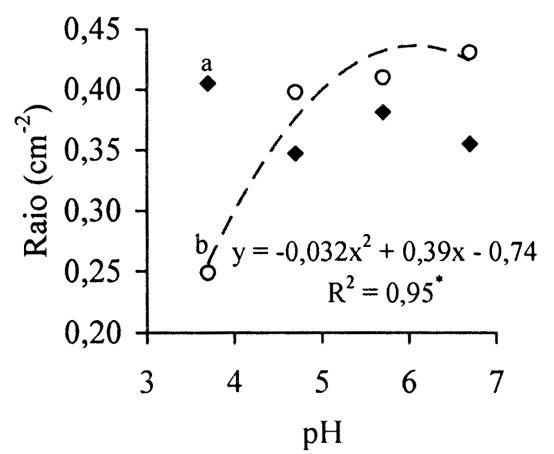

b)

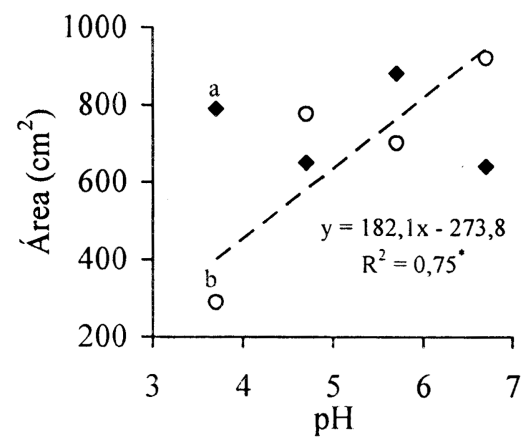

d)

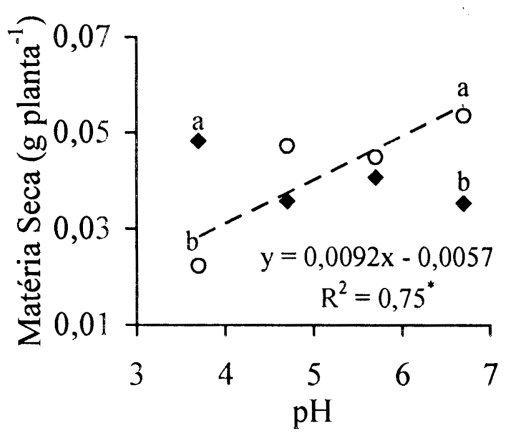

e)
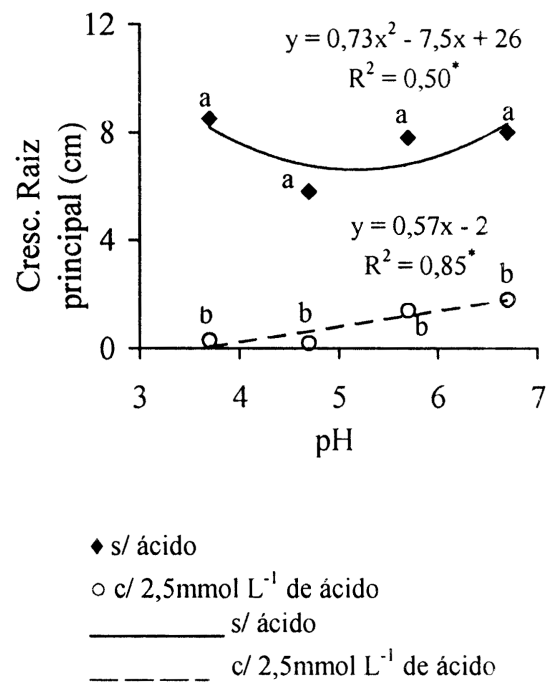

Figura 1 - Valores médios do comprimento total (a), área (b), raio (c), massa de matéria seca (d) e crescimento da raiz principal (e) do sistema radicular de plantas de arroz da cultivar "BRS 7" sob efeito do ácido acético em diferentes valores de pH. UFPel, Pelotas/2006.

Letras distintas nos gráficos para cada valor de $\mathrm{pH}$ diferem estatisticamente pelo teste de Duncan a 5\% de significância.

*Nível de significância 5\%. 
a)

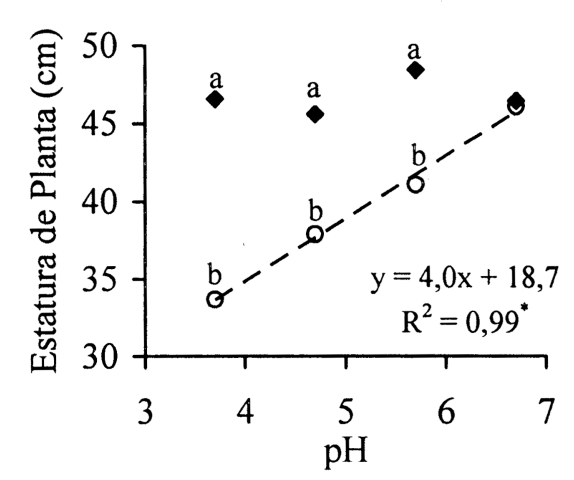

b)

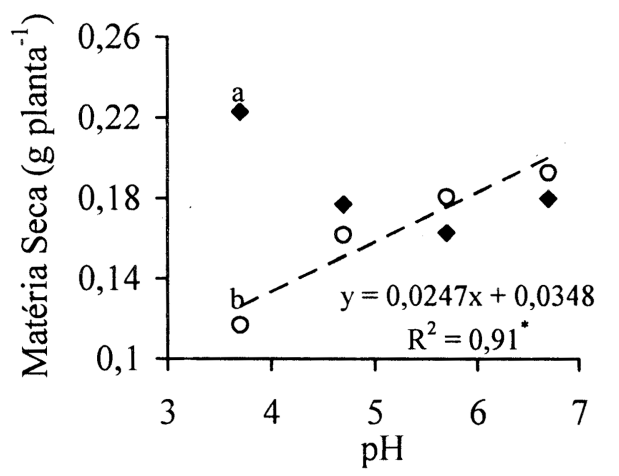

s/ ácido
c/ 2,5mmol L ${ }^{-1}$ de ácido
_ _ _ c c $2,5 \mathrm{mmol} \mathrm{L}^{-1}$ de ácido

Figura 2 - Valores médios da estatura (a) e massa de matéria seca (b) da parte aérea das plantas de arroz da cultivar "BRS 7” sob efeito do ácido acético em diferentes valores de pH. UFPel, Pelotas/2006.

Letras distintas nos gráficos para cada valor de $\mathrm{pH}$ diferem estatisticamente pelo teste de Duncan a $5 \%$ de significância.

*Nível de significância 5\%. aérea das plantas foi necessário 8,0 $\mathrm{mmol} \mathrm{L}^{-1}$ de ácido para atingir o mesmo percentual de inibição. Já KOPP et al. (2007) verificaram uma redução do comprimento radicular de $50 \%$ e $40 \%$ na parte aérea de plantas de arroz, na presença de $10 \mathrm{mmol} \mathrm{L}^{-1}$ de ácido acético. Neste trabalho com 2,5mmol L-1 de ácido acético a redução na parte aérea foi de $27 \%$ quando o $\mathrm{pH}$ foi diminuído de 6,7 para 3,7 (Figura 2).

Os principais efeitos dos ácidos orgânicos estão associados à inibição da germinação e da expansão radicular, como resultado de lesões causadas ao tecido meristemático da radícula ou de limitações à respiração, conduzindo à inibição da divisão celular (CAMARGO et al., 1993). ARMSTRONG \& ARMSTRONG (2001) analisaram os efeitos fisiológicos relacionados à toxidez pelos ácidos orgânicos em arroz e verificaram que eles causam inibição da divisão celular na raiz que está diretamente em contato com os ácidos. Assim, provavelmente, essa seja a razão principal para o menor crescimento radicular e menor acúmulo de matéria seca. Esses autores verificaram sintomas de amarelecimento das células externas das raízes com apenas 24 horas sob efeito do ácido acético, provavelmente, devido ao acúmulo de polissacarídeos contendo compostos fenólicos.

O ácido acético diminuiu a concentração e a quantidade acumulada de $\mathrm{N}, \mathrm{P}$ e K na parte aérea do arroz (Tabela 1), na maioria dos valores de $\mathrm{pH}$ da solução nutritiva. A absorção de Ca e Mg não foi afetada pelo ácido nos diferentes valores de $\mathrm{pH}$. Houve interação significativa entre os fatores $\mathrm{pH}$ e ácido acético na concentração de $\mathrm{P}$ e K no tecido das plantas. Diversos autores (SOUSA \& BORTOLON, 2002; SCHMIDT et al., 2007) também observaram diminuição na absorção de nutrientes como efeito da toxidez por ácidos orgânicos, que pode estar relacionado ao menor crescimento radicular e à inibição de processos responsáveis pela produção de energia na raiz para absorção ativa de nutrientes (RAO \& MIKKELSEN, 1977; TAKENAGA, 1995a).

A diminuição na concentração de nutrientes nas plantas pode estar relacionada também à degradação das membranas celulares. Segundo MARSCHNER (1995), ácidos monocarboxílicos, como o acético, alteram a composição dos ácidos orgânicos na membrana plasmática, promovendo um decréscimo da proporção dos ácidos polinsaturados, afetando propriedade importante da membrana, como a seletividade, e aumentando o extravasamento de solutos. Isso foi comprovado também por SOUSA et al. (2002), que observaram aumentos de até 50\% de potássio em solução nutritiva contendo diferentes doses de ácido acético, como resultado da exsudação oriunda do sistema radicular do arroz. $\mathrm{O}$ efeito do $\mathrm{pH}$ sobre a concentração e a quantidade total acumulada de nutrientes na parte 
Tabela 1 - Concentrações de nutrientes $\left(\mathrm{g} \mathrm{kg}^{-1}\right)$ e quantidade total acumulada de nutrientes (mg vaso-1) na parte aérea da cultivar de arroz “BRS 7” em função de diferentes valores de pH e doses de ácido acético na solução nutritiva. UFPel, Pelotas/2006.

\begin{tabular}{|c|c|c|c|c|c|}
\hline \multirow{2}{*}{$\begin{array}{l}\text { Ácido Acético } \\
\left(\mathrm{mmol} \mathrm{L}^{-1}\right)\end{array}$} & \multicolumn{5}{|c|}{ 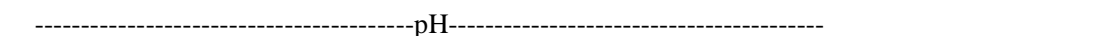 } \\
\hline & 3,7 & 4,7 & 5,7 & 6,7 & Média \\
\hline \multicolumn{6}{|c|}{ - } \\
\hline 0 & 18,8 & 21,1 & 18,7 & 21,5 & $20,0 \mathrm{a}$ \\
\hline \multirow[t]{2}{*}{2,5} & 12,9 & 14,5 & 15,8 & 12,4 & $13,9 \mathrm{~b}$ \\
\hline & & & & --- & \\
\hline 0 & $7,0 \mathrm{a}$ & 6,5 a & $6,0 \mathrm{a}$ & 5,4 a & 6,2 \\
\hline \multirow[t]{2}{*}{2,5} & $4,6 \mathrm{~b}$ & $4,0 \mathrm{~b}$ & $4,6 \mathrm{~b}$ & $4,0 \mathrm{~b}$ & 4,3 \\
\hline & & 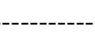 & 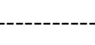 & ---- & \\
\hline 0 & 35,4 a & 36,3 a & 37,0 a & 37,1 a & 36,5 \\
\hline 2,5 & $26,6 \mathrm{~b}$ & $26,4 \mathrm{~b}$ & $29,4 \mathrm{~b}$ & $27,3 \mathrm{~b}$ & 27,4 \\
\hline 0 & 8,6 & 9.4 & 9,8 & 9.4 & $9.3 \mathrm{a}$ \\
\hline \multirow[t]{2}{*}{2,5} & 10,8 & 11,7 & 9,1 & 9,1 & $10,2 \mathrm{a}$ \\
\hline & & ---- & & ----- & \\
\hline 0 & 4,1 & 4,6 & 4,5 & 4,0 & $4,3 \mathrm{a}$ \\
\hline 2,5 & 4,5 & 3,6 & 3,9 & 3,4 & 3,9 a \\
\hline 0 & 12,5 & 11,4 & 10,0 & 11,5 & $11,4 \mathrm{a}$ \\
\hline \multirow[t]{2}{*}{2,5} & 4,5 & 7,0 & 7,1 & 7,2 & $6,5 \mathrm{~b}$ \\
\hline & & 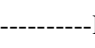 & & 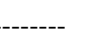 & \\
\hline 0 & 4,6 a & 3,5 a & 3,2 a & 2,9 a & 3,6 \\
\hline \multirow[t]{2}{*}{2,5} & $1,6 \mathrm{~b}$ & $2,0 \mathrm{~b}$ & $2,1 \mathrm{a}$ & 2,3 a & 2,0 \\
\hline & & 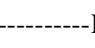 & & ----- & \\
\hline 0 & 23,6 & 19,6 & 19,8 & 21,0 & $21,0 \mathrm{a}$ \\
\hline \multirow[t]{2}{*}{2,5} & 9,3 & 12,9 & 13,0 & 15,8 & $12,8 \mathrm{~b}$ \\
\hline & & 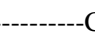 & ----. & -------- & \\
\hline 0 & 5,7 & 4,9 & 5,2 & 5,1 & $5,2 \mathrm{a}$ \\
\hline 2,5 & 3,8 & 5,7 & 3,9 & 5,2 & 4,7 a \\
\hline 0 & & & & & 25 \\
\hline 2,5 & 1,6 & 1,7 & 1,8 & 2,0 & $1,8 \mathrm{a}$ \\
\hline
\end{tabular}

Médias seguidas de letras distintas nas colunas em relação a cada nutriente diferem estatisticamente pelo teste de Duncan a 5\% de significância.

aérea das plantas foi pequeno (Tabela 2). Na presença de ácido acético, o aumento do $\mathrm{pH}$ causou aumento na concentração de $\mathrm{N}$ (22\%) e diminuição na concentração de Ca (19\%), enquanto que, na ausência de ácido acético, a concentração e a quantidade acumulada de $\mathrm{P}$ diminuíram com o aumento do $\mathrm{pH}$. O efeito tóxico do ácido acético parece ser direto na absorção de cálcio, pois o aumento do $\mathrm{pH}$ afetou pouco a absorção deste pelas plantas. Existe uma interação entre o cálcio e o crescimento da raiz em diferentes valores de $\mathrm{pH}$ (MURATA et al., 2003). As paredes celulares em crescimento se estendem mais rapidamente em $\mathrm{pH}$ ácido do que em $\mathrm{pH}$ neutro por um fenômeno conhecido como crescimento ácido (TAIZ \& ZEIGER, 2004) e tal efeito é atenuado na presença de cálcio (ASLAM et al., 1995).
O aumento do pH da solução nutritiva diminuiu a toxidez pelo ácido acético, indicando uma possibilidade de redução dos efeitos tóxicos do ácido pela utilização da calagem. Todavia, experimentos a campo, com calcário, precisariam ser desenvolvidos para confirmar esta hipótese.

\section{CONCLUSÕES}

O incremento de $\mathrm{pH}$ da solução nutritiva de 3,7 para 6,7 reduziu o efeito tóxico do ácido acético em plantas de arroz da cultivar "BRS 7”, aumentando o comprimento da raiz em 90\% e da parte aérea em 37\%. Os teores de $\mathrm{N}$ na parte aérea da cultivar de arroz "BRS 7” aumentaram em 22\% e os teores de Ca diminuíram 
Tabela 2 - Equações de regressão entre valores de $\mathrm{pH}(\mathrm{x})$ e concentração nutrientes $\left(\mathrm{g} \mathrm{kg}^{-1}\right)$ e quantidade acumulada de nutrientes na parte aérea (mg vaso $\left.{ }^{-1}\right)$, na ausência de ácido acético $\left(\mathrm{y}_{1}\right)$, e com $2,5 \mathrm{mmol} \mathrm{L}^{-1}$ de ácido acético $\left(\mathrm{y}_{2}\right)$ em solução nutritiva da cultivar de arroz “BRS 7”. UFPel, Pelotas/2006.

\begin{tabular}{|c|c|c|c|c|}
\hline \multirow{2}{*}{ Nutrientes } & \multirow{2}{*}{$\begin{array}{c}\text {---S/ ácido acético }\left(\mathrm{y}_{1}\right)--- \\
\text { Equação }\end{array}$} & \multicolumn{3}{|c|}{---C/ ácido acético $\left(\mathrm{y}_{2}\right)---$} \\
\hline & & $r^{2}$ & Equação & $r^{2}$ \\
\hline & -----------------------------. & ----- & centração --------------------------- & ------ \\
\hline $\mathrm{N}$ & ns & & $\mathrm{y}_{2}=-1,24 \mathrm{x}^{2}+12,87 \mathrm{x}-17,96$ & $0,87^{*}$ \\
\hline $\mathrm{P}$ & $\mathrm{y}_{1}=-0,552 \mathrm{x}+9,11$ & $0,99^{*}$ & ns & \\
\hline $\mathrm{K}$ & ns & & ns & \\
\hline $\mathrm{Ca}$ & ns & & $y_{2}=-0,765 x+14,16$ & $0,60^{*}$ \\
\hline $\mathrm{Mg}$ & ns & & ns & \\
\hline & ---------------- & -------- & de Acumulada -------------------- & ------ \\
\hline $\mathrm{N}$ & ns & & ns & \\
\hline $\mathrm{P}$ & $\mathrm{y}_{1}=-0,534 \mathrm{x}+6,32$ & $0,88^{*}$ & ns & \\
\hline $\mathrm{K}$ & ns & & ns & \\
\hline $\mathrm{Ca}$ & ns & & ns & \\
\hline $\mathrm{Mg}$ & ns & & ns & \\
\hline
\end{tabular}

* Nível de significância 5\%. ns = não-significativo.

em $19 \%$ com o aumento do $\mathrm{pH}$ com $2,5 \mathrm{mmol} \mathrm{L}^{-1}$ de ácido acético.

\section{AGRADECIMENTOS}

Os autores agradecem à Fundação de Amparo à Pesquisa do Estado do Rio Grande do Sul (FAPERGS) e à Coordenação de Aperfeiçoamento de Pessoal de Nível Superior (CAPES), pela concessão de bolsas às alunas Fabiana Schmidt e Magali de Ávila Fortes.

\section{REFERÊNCIAS}

ARMSTRONG, J.; ARMSTRONG, W. Rice and Phragmites: effects of organic acids on growth, root permeability, and radial oxygen loss to the rhizosphere. American Journal of Botany, Sant Louis, v.88, n.8, P.1359-1370, 2001.

ASLAM, M. et al. Effect of $\mathrm{pH}$ and calcium on short-term $\mathrm{NO}_{3}$ - fluxes in roots of barley seedlings. Plant Physiology, Rockville, v.108, n.2, p.727-734, 1995.

ATKINS, P.; JONES, L. Princípios de química: questionando a vida moderna e o meio ambiente. Porto Alegre: Bookman, 2001. 914p.

BOHNEN, H. et al. Ácidos orgânicos na solução de um gleissolo sob diferentes sistemas de cultivo com arroz irrigado. Revista Brasileira de Ciência do Solo, Campinas, v.29, n.3, p.475480, 2005.

CAMARGO, F.A. de O. et al. Efeito dos ácido acético e butírico sobre o crescimento de plântulas de arroz. Pesquisa Agropecuária Brasileira, Brasília, v.28, n.9, p.1011-1018, 1993.

HARPER, S.H.T.; LYNCH, J.M. The chemical components and decomposition of wheat straw leaves, internodes and nodes.
Journal of the Science of Food and Agriculture, London, v.32, n.11, p.1057-1062, 1981.

KOPP, M.M. et al. Níveis críticos dos ácidos acético, propiônico e butírico para estudos de toxicidade em arroz em solução nutritiva. Acta Botânica Brasílica, São Paulo, v.21, n.1, p.147-154, 2007.

LYNCH, J.M. Biotecnologia do Solo : Fatores microbiológicos na produtividade agrícola. São Paulo: Manole, 1986. 209p.

MACHADO, A. Winstat - Sistema de análises estatísticas para o Windows. Versão 1.0. Pelotas: NIA - Núcleo de Informática Aplicada, Universidade Federal de Pelotas, 2001. CD-ROM.

MARSCHNER, H. Mineral nutrition of higher plants. London: Academic, 1995. 889p.

MENGEL, K.; KIRKBY, E.A. Principles of plant nutrition. 4.ed. Bern Switzerland: International Potash Institute, 1987. $655 p$.

MURATA, M.R. et al. Effect of solution $\mathrm{pH}$ and calcium concentration on germination and early growth of groundnut. Journal of Plant Nutrition, New York, v.26, n.6, p.12471262, 2003.

PONNAMPERUMA, F.N. The chemistry of submerged soils. Advances in Agronomy, New York, v.24, n.22, p.29-96, 1972.

RAO, D.N.; MIKKELSEN, D.S. Effect of rice straw incorporation on productions of organic acids in a flooded soil. Plant and Soil, The Hague, v.47, n.2, p.303-311, 1977.

SCHMIDT, F. et al. Toxidez pelos ácidos propiônico e butírico em plântulas de arroz. Ciência Rural, Santa Maria, v.37, n.3, p.720-726, 2007.

Ciência Rural, v.38, n.6, set, 2008. 
SOUSA, R.O. et al. Efeito do ácido acético na absorção de potássio em arroz. In: CONGRESSO BRASILEIRO DE CIÊNCIA DO SOLO, 2003, Ribeirão Preto. Anais... Botucatu: SBCS/ UNESP, 2003. CD-ROM.

SOUSA, R.O. et al. Estudos preliminares sobre a toxidez por ácido acético em plantas de soja. In: REUNIÃO TÉCNICA SOBRE A DIVERSIFICAÇÃO DO USO DE VÁRZEAS DE CLIMA TEMPERADO, 2002, Pelotas. Anais... Pelotas: Embrapa Clima Temperado, 2002. CD-ROM.

SOUSA, R.O. Oxirredução em solos alagados afetada por resíduos vegetais. 2001. 164f. Tese (Doutorado em Ciência do Solo) - Faculdade de Agronomia, Universidade Federal do Rio Grande do Sul, Porto Alegre.

SOUSA, R.O.; BORTOLON, L. Crescimento radicular e da parte aérea do arroz (Oryza sativa L.) e adsorção de nutrientes, em solução nutritiva com diferentes concentrações de ácido acético. Revista Brasileira de Agrociência, Pelotas, v.8, n.3, p.231-235, 2002.
TAIZ, L.; ZEIGER, E. Fisiologia vegetal. 3.ed. Porto Alegre: Artmed, 2004. 719p.

TAKENAGA, H. Nutrient absorption in relation to environmental factors. In: MATSUO, T. et al. Science of the rice plant: physiology. Tokyo: Nosan Gyoson Bunka Kyokai, 1995a. p.278-294.

TAKENAGA, H. Internal factores in relation to nutrient absorption. In: MATSUO, T. et al. Science of the rice plant: physiology. Tokyo: Nosan Gyoson Bunka Kyokai, 1995b. p.294-309.

TEDESCO, M.J. et al. Análise de solo, plantas e outros materiais. 2.ed. Porto Alegre: Departamento de Solos da UFRGS, 1995. 174p. (Boletim Técnico de Solos, 5).

TENNANT, A.A. Test of modified line intersect method of estimating root length. Journal of Applied Ecology, London, v.63, n.6, p.995-1001, 1975. 